\title{
El presente como archivo: inscripciones del futuro en el artivismo prepandémico
}

\author{
The present as an archive: future inscriptions in pre-pandemic \\ artivism \\ Lorena Verzero \\ CONICET-UBA \\ lorenaverzero@gmail.com
}

\section{Resumen}

El artículo parte de la pregunta sobre los futuros que nos es posible imaginar y, para tantear alternativas, se centra en prácticas de activismo artístico desarrolladas hasta el inicio de la pandemia por Covid-19. La indagación sobre experiencias artivistas se funda en la hipótesis de que se trata de prácticas que encarnan en sî mismas elementos particularmente especiales para imaginar y construir futuros alternativos a los que nos ofrece el status quo. Se profundiza en el análisis de algunos casos en los que la autora misma ha intervenido, como modo de exponer la potencia transformadora de la conjunción entre cuerpo y palabra, experiencia y reflexión crítica.

Palabras clave: artivismo, memoria, futuros

\begin{abstract}
This article stems from the question around the possible futures we can imagine. In exploring alternatives, it focuses on artistic activism practices developed up to the beginning of the COVID-19 pandemic. It investigates artivistic experiences based on the hypothesis that these practices embody particularly special elements to imagine and build alternative futures to those offered by the status quo. The analysis will study in more depth some cases where the present author has intervened, as a way of showing the transformative potential of bringing together body and words, experience and critical reflection.
\end{abstract}

Keywords: artivism, memory, futures 
La pregunta por cómo imaginamos los futuros posibles resulta sumamente estimulante, puesto que son muchas y múltiples las variables de nuestra coyuntura histórica que nos harían desembocar en pensamientos pesimistas y hasta nihilistas sobre hacia dónde están yendo nuestras sociedades guiadas por poderes sin escrúpulos. Encuentro un desafío, no obstante, en que la pregunta aislada parece a priori arrastrar consigo el mandato de imaginar futuros mejores. ¿Cómo nosotros, intelectuales, artistas, gente de la cultura, no vamos a imaginar estrategias para construir futuros mejores?

La pregunta por los futuros posibles me lleva otra vez a Benjamin (2005), en particular a la reiteración de la idea que toma de Jules Michelet de que "cada época sueña a la siguiente" (35). De acuerdo con esa idea, el presente como tiempo histórico es la construcción que el pasado ha hecho de él. En mis trabajos sobre teatro militante (Verzero Teatro militante), avancé en esta línea respecto de las relaciones del presente con el pasado reciente. Mi intención ahora es pensar en el presente como pasado de los futuros que imaginamos.

Si bien, entonces, el presente es resultado del pasado, la historia ha preparado el presente como su futuro posible. En este sentido, y dado que el futuro encierra la imposibilidad de existir, el presente — además de ser factualidad — aparece como posibilidad. En su Tesis II, Benjamin postula dos definiciones para la idea de presente: el presente como el aquí y ahora, lo que ha llegado a ser, la consecuencia del pasado; y el presente como posibilidad, forjado en el pasado fracasado, en los pasados que no han llegado a ser. Así, si el presente real es acto, el presente posible es potencia. El presente como posibilidad se cimienta en el pasado que no ha podido coagular. En este sentido, cada presente ya no es sólo continuidad o consecuencia del pasado. Para trabajar con el pasado reciente, considero fundamental retomar la referencia a esta cuestión que formula Reyes Mate en el marco de un sesudo análisis de las Tesis de Benjamin. Si llamamos a la posibilidad presente — dirá Mate (72) - es porque reconocemos a esa historia frustrada un derecho a ser, a lograrse, a la felicidad, es decir, a ser redimida. Esta idea nos permite tomar distancia del presente como acto, como factualidad, y pensarlo en todas sus dimensiones de posibilidades; y por ende, imaginar no sólo futuros posibles, sino también, futuros imposibles; planear desanclajes, desvíos, interrupciones y disrupciones.

Por otra parte, los debates sobre las ventajas y las limitaciones de historizar el presente, que provienen ya de los años 70, resultan iluminadoras para situar las reflexiones sobre la contemporaneidad en un marco teórico y material (Díaz Munizaga). El Instituto de Historia del Tiempo Presente de París constituyó un espacio intelectual clave de esta línea de pensamiento. Francois Bédarida, fundador 
y primer director del Instituto (1978-1990), definía el presente como “el tiempo de la experiencia vivida" (22). "Se trata — continúa Bédarida—, verdaderamente, de un terreno movedizo, con periodizaciones más o menos elásticas, con aproximaciones variables, con adquisiciones sucesivas. Un tiempo caracterizado por el hecho de que existen testigos y una memoria viva de donde se desprende el papel específico de la historia oral" (22). La Historia del Tiempo Presente opera, entonces, como marco teórico que al mismo tiempo brinda herramientas analíticas para pensar la contemporaneidad.

Comencé a pensar este artículo de cara a una presentación en el Foro de las Artes que organizan la Dirección de Creación Artística, Vicerrectoría de Investigación y Desarrollo, y la Vicerrectoría de Extensión y Comunicaciones de la Universidad de Chile, y que tuvo lugar en la ciudad de Santiago entre el 8 y el 10 de octubre de 2019, pocos días antes del estallido. Como anticipando no sólo la revuelta, sino también la pandemia que prosiguió, el seminario se tituló "Los futuros imaginados". ${ }^{1}$ Algunas de las preguntas formuladas como disparadores de este encuentro me resonaban muy especialmente en relación con mi campo de estudios y, tras los episodios del "despertar" chileno sumados a la experiencia de pandemia por Covid-19, los interrogantes sobre la construcción de futuros resultan insoslayables. Entre las preguntas formuladas en el texto de presentación del Foro de las Artes, me interesa retomar las siguientes:

¿Cuáles son las expresiones artísticas actuales (llámese "contemporáneo" o no) que impactan en el campo social y cuáles son los efectos de su quehacer? ¿Qué convierte a una expresión artística en algo necesario desde el punto de vista social? ¿Cómo el arte del presente lidia con esa demanda? . . ¿ ¿Cuáles son los futuros que el arte está imaginando actualmente? ¿Cómo el estatuto del artista ha cambiado, y seguirá cambiando, en relación con el modo en que las tecnologías de producción y difusión del arte han modificado la relación entre artista, materia y forma? (s/n). ${ }^{2}$

Una de las figuras destacadas en la actualidad en el campo de la historiografía del presente, que integra y ha dirigido el mencionado Instituto del Tiempo Presente, es Henry Roussó (2012). En 2017 Roussó visitó la Argentina y observó la dimensión que la historia toma en nuestros países y, muy particularmente, la

1 Video de difusión del Foro de la Artes 2019

2 Conferencias del Seminario Internacional "Los futuros imaginados: Memorias, feminismos y representaciones críticas en el arte" 
dimensión que en nuestras sociedades cobra en relación con la memoria. Según el historiador francés:

Esta resonancia se debe a que la epistemología particular de la historia reciente tal como emergió en los años setenta, paralelamente a una nueva historia de la memoria, dos fenómenos que fueron concomitantes, se inscribe en una época general, en un régimen de historicidad en el que la memoria se ha convertido en un valor fundamental — que no está exento en algunos casos de un cierto fetichismo (2).

En esa conferencia, Russó se va a centrar en una historiografía de la memoria con la intención de corroborar la hipótesis de que "este modo de escribir la historia, esta sensibilidad en torno a la memoria y al modo de investigar la historia contemporánea, se ha vuelto un fenómeno mundial" (2). Contrariamente a su voluntad de establecimiento de una teoría global, es mi intención hoy tomar alguna de sus argumentaciones para pensar los modos en que la memoria (y más específicamente, la memoria en el campo artístico) tiene lugar en nuestro presente como modo de imaginar futuros y que, de algún modo, funciona como respuesta a las preguntas anteriores.

\section{Artivismo: elementos para imaginación del futuro}

Me he dedicado largamente a la investigación sobre la construcción de memorias en el teatro argentino, haciendo algunas aproximaciones a estas problemáticas en los demás países del Cono Sur. ${ }^{3}$ En dicho trayecto, he constatado la emergencia de nuevos modos de incidencia desde las prácticas artísticas en las construcciones de la historia y, por ende, en sus relaciones con la memoria.

Estas nuevas prácticas se originan en el marco de la restauración neoliberal que se dio en los últimos años en Argentina en consonancia con el desplazamiento político propiciado en gran parte de los países de la región y del mundo occidental. Ya a partir de los últimos años del segundo gobierno progresista de Cristina Fernández (20112015) comenzaron a organizarse colectivos artísticos que desarrollaban distinto tipo de tácticas de intervención en el espacio público. Con la asunción de Mauricio Macri como presidente (2011-2015) y la instauración del neoliberalismo feroz, las prácticas de resistencia y los intentos de construcción de micropolíticas alternativas que tímidamente iban surgiendo, se fortalecieron, se multiplicaron y potenciaron. Entre ellas, las experiencias artísticas han ocupado un lugar preponderante.

3 Algunas de mis publicaciones se encuentran en: conicet.academia.edu 
Se trata de experiencias siempre desarrolladas por colectivos. Estos se reúnen a partir de diferentes tipos de convocatoria y con diversas modalidades de gestión, pero con finalidades de asociación en nuevos tipos de grupalidad, de entretejido de nuevos lazos sociales, de configuración de nuevos modos de incidencia en lo social-político y de desarrollo de operaciones estéticas innovadoras. Estas prácticas se enmarcan en la historia del activismo artístico en el siglo XX y conectan con experiencias de la historia reciente latinoamericana. En términos generales, combinan un interés estético con una intencionalidad (micro)política directa, y se desarrollan de manera colectiva en el interregno entre el arte, la política, la comunicación y la performance.

Los colectivos contemporáneos se caracterizan por configurar un tipo de artivismo que desafía no sólo definiciones de ciudad(anía), de corporalidad y de virtualidad, sino también la noción del arte y la experiencia estética como actividad relativamente autónoma de las lógicas dominantes. Además de su presencia física, los grupos usan Internet y redes sociales con diversas funcionalidades, desde generar visibilidad y tener acceso a un público más amplio, hasta construir las performances en un entorno con presencialidades diversas. Con estas acciones se interpela a un nuevo tipo de subjetividad, que se configura no sólo en el espacio físico, sino virtualmente a través de las redes sociales, posibilitando una participación diferida en el espacio y en el tiempo. Los medios son implementados como recursos para crear acciones y escenas híbridas y autoreflexivas que exponen críticamente a los espectadores las fuerzas sociales que contribuyen a su construcción y a la construcción de las subjetividades presentes en ellas. Con todo esto, no sólo se redefine el lugar de espectación, sino también los de producción artística, intervención política y espacio público.

El activismo artístico contemporáneo intenta despertar a la sociedad de las ilusiones del neoliberalismo, señalando la violencia física y simbólica, subvirtiendo los usos del espacio público, subrayando el carácter antidemocrático de la hegemonía patriarcal y de los modos de organización social, política y económica que de él se desprenden y están naturalizados por el sentido común. Algunos de los colectivos se vinculan a corrientes del feminismo o a movimientos sociales, como "Barrios x la Memoria" o "Ni una menos".

Podría decirse que estas características generales definen ampliamente el fenómeno, pero sin embargo, se trata de un tipo de práctica que constantemente se escurre de una definición cerrada. Por ejemplo, si bien una de sus características centrales es la intervención en el espacio público de la ciudad, el artivismo también ocurre en otro tipo de espacios, como centros culturales, universidades y sitios de 
memoria. En el mismo sentido, subrayamos su carácter anti-institucional, sus tensiones y sus disputas con la institución (desde instituciones estatales o culturales, hasta la institución arte) pero, por ejemplo, los museos incluyen intervenciones de este tipo, incluso privilegiándolas en las curadurías o promocionando convocatorias específicas de intervención artístico-política. Además, algunas de las acciones se enmarcan en la lógica del campo cultural (se dan en sala, con una periodicidad de funciones y cobrando entrada) sin dejar de activar política y estéticamente, y de contener una cantidad de criterios a partir de los cuales podemos seguir considerándolas artivistas.

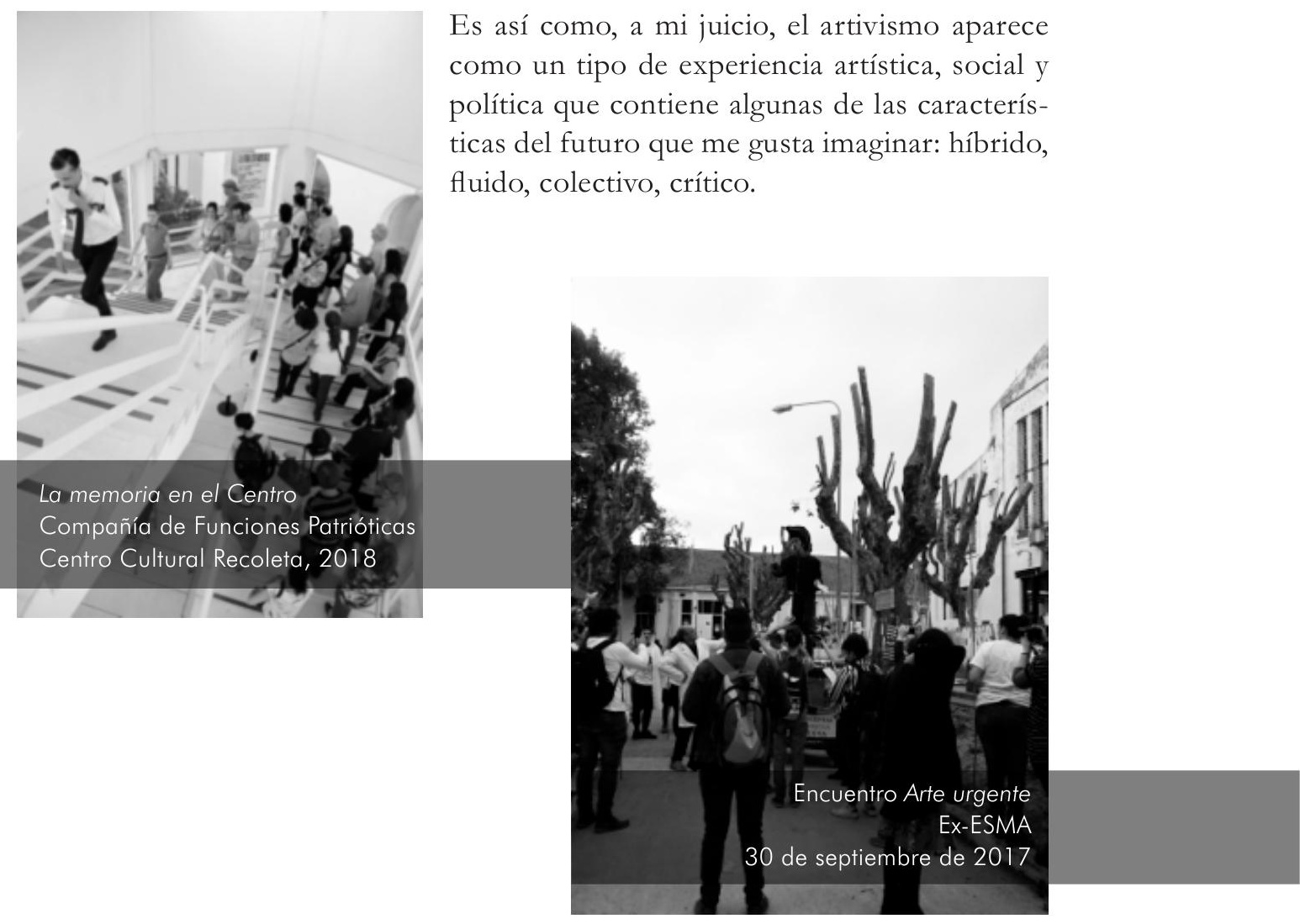




\section{Artivismo y memoria}

En lo que respecta a la construcción de memorias, si durante las primeras décadas del siglo el teatro argentino se había caracterizado por la centralidad de una mirada sobre la historia reciente (Verzero 2019), los colectivos artivistas contemporáneos aparentemente amplían esa temporalidad, poniendo en escena acciones que reconstruyen no sólo los años de la última dictadura (por ejemplo, las acciones centrales del proyecto Relato situado de la Compañía de Funciones Patrióticas, Una topografía de la memoria (2016-2017); Almagro Tiene Memoria (2017) y las obras de recorrido que las continuaron, El sentido de la memoria (2018), Los barrios tienen memoria (2018), Memoria de Campo de Mayo (2018)); sino también, la historia nacional y las relaciones con el peronismo (Relato situado, Acción de memoria urbana, 2015); la conquista de América (como Proyecto 52/10 de FUNO, Colectivo Fin de UN MundO, 2012); la historia de corporaciones y explotación de los últimos siglos (\#¿Quién elige?, FACC, Fuerza Artística de Choque Comunicativo, 2017), la historia de Internet, del hacktivismo y de las lógicas tecnocráticas de los años '80 y '90 (Ciberpunks del Colectivo Dominio Público, 2016).

Las acciones son en todos los casos intertextuales y colaborativas. Todas implican al público de distinta manera (como participante, como en los Relatos situados o el final de Proyecto 52/10; o como espectador, como en \#iQuién elige? ), interrumpiendo en su cotidianeidad o convocándolo en un día y hora determinados para encontrarse en un espacio). Estas acciones se desarrollan en distinto tipo de espacios (la mayoría de ellas en la calle en la ciudad de Buenos Aires, pero algunas se dan en otras ciudades del país (las acciones 1, 2 y 3 de \# ¿Quién elige?, y algunas, en espacios cerrados ligados a la institución arte (tal es el caso de Ciberpunks, que se dio en la sala Hasta Trilce, un espacio cultural independiente de la ciudad de Buenos Aires).

La apertura a la participación constituye una de las características centrales de estos colectivos. Esta apertura puede tener que ver con la participación del público durante la experiencia o con la conformación del grupo. Ambos tipos de relaciones se dan de múltiples maneras: el público puede ser invitado a participar si lo desea, su participación puede ser indispensable para que la acción se desarrolle o puede simplemente participar como observador a la manera de un espectador de teatro tradicional, y estos modos de participación se generan y se gestionan de las maneras más diversas. En lo que respecta a la inclusión de integrantes en los colectivos, algunos de ellos son abiertos con ciertas reglas (FUNO, Arda), y otros convocan a artistas, artistas no profesionales u otro tipo de invitados para la 


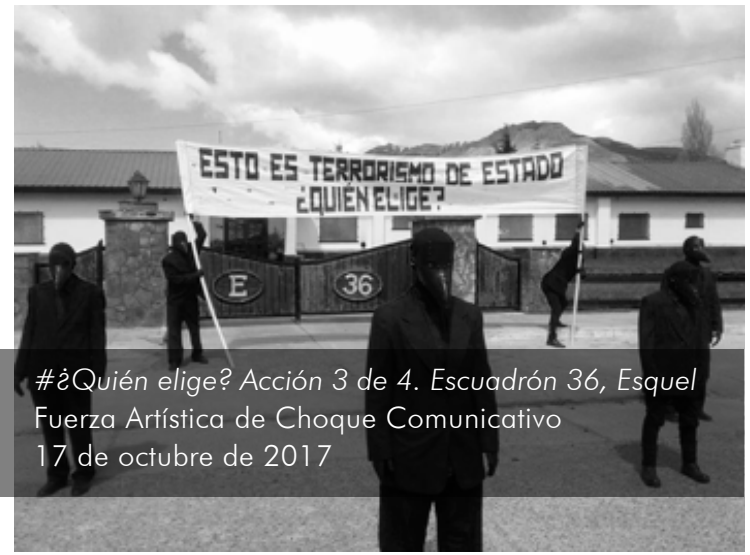

realización de alguna acción en particular (Compañía de Funciones Patrióticas, FACC). Todo esto potencia el trabajo creativo en un espacio híbrido entre la investigación y la práctica artística. Este rasgo constituye una de las problemáticas centrales del arte actual y el artivismo, por su propia configuración, resulta particularmente permeable a esos intercambios.

En el mismo sentido, los colectivos o sus integrantes suelen desplegar reflexiones sobre su propio trabajo. El proceso creativo está fuertemente marcado por debates y dilemas que demandan reflexiones y, en algunos casos, estas se vuelcan en resultados que acompañan las acciones como paratextos o, incluso, como publicaciones de los mismos artistas.

El artivismo constituye, así, una actividad en la que creación e investigación aparecen particularmente imbricadas. El carácter crítico del activismo, la reflexión que motoriza toda acción y la creatividad puesta en juego en las intervenciones, hace que el artivismo resulte particularmente propicio para romper con las fronteras dis-
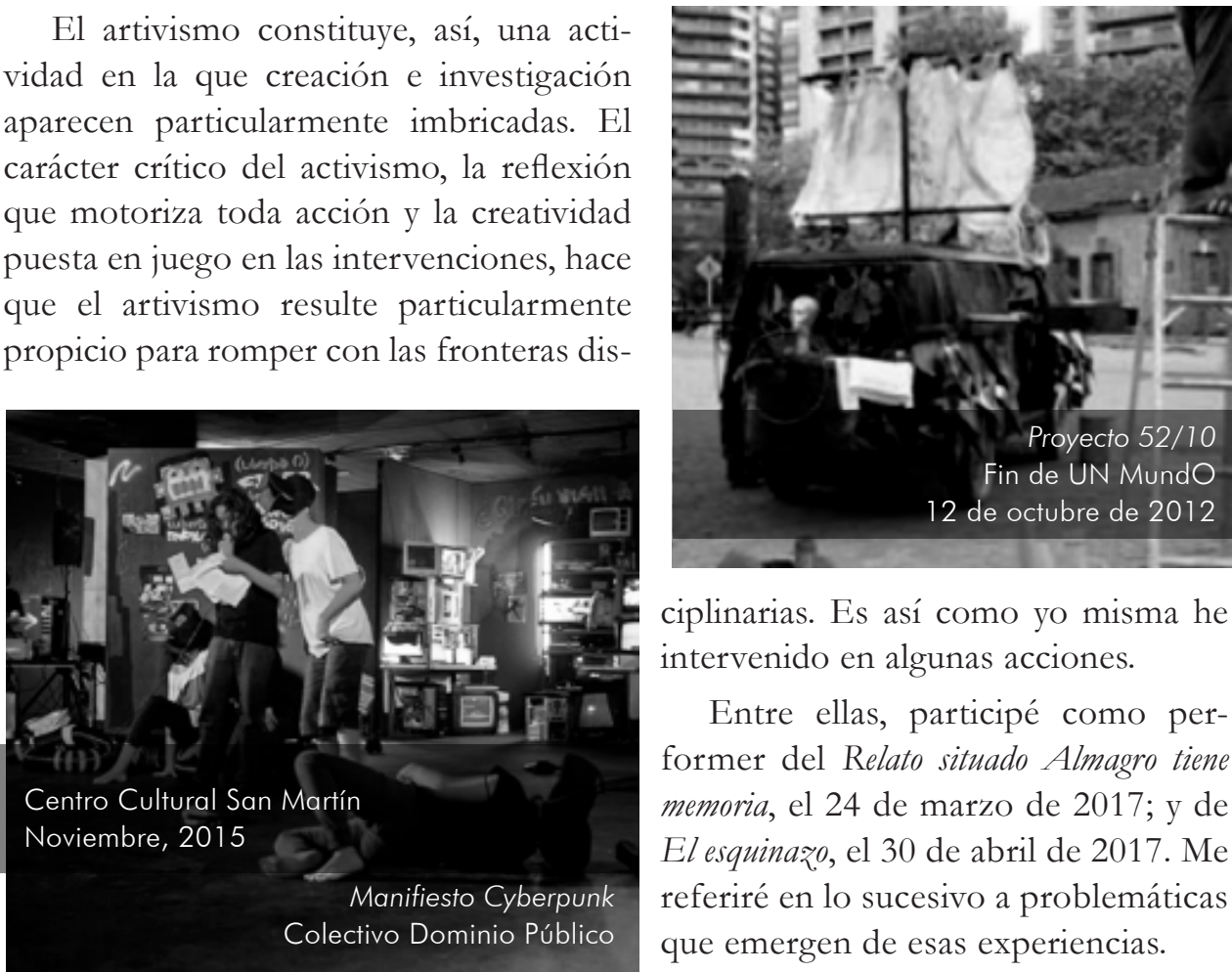

ciplinarias. Es así como yo misma he intervenido en algunas acciones.

Entre ellas, participé como performer del Relato situado Almagro tiene memoria, el 24 de marzo de 2017; y de El esquinazo, el 30 de abril de 2017. Me referiré en lo sucesivo a problemáticas que emergen de esas experiencias. 


\section{Artivismo: entre la memoria colectiva y la memoria individual}

Almagro tiene memoria 4 es una obra de recorrido de Compañía de Funciones Patrióticas, que aumenta la propuesta realizada anteriormente Una topografía de la memoria (2016). Esta última se constituirá en el sello del grupo, y consistió en una deriva, es decir, en un recorrido a pie, por una zona del barrio de Almagro, con la realización de acciones en algunas "baldosas por la memoria".

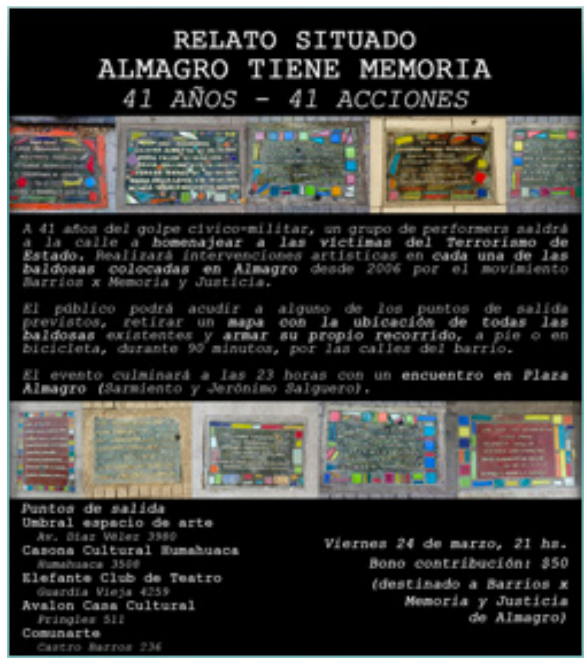

Afiches de difusión Relato situado. Almagro tiene memoria, 2017 Compañía de Funciones Patrióticas

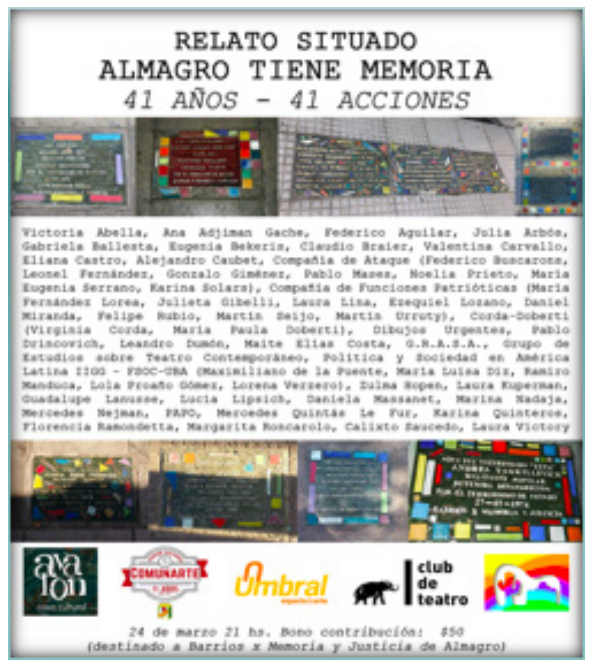

Realizada en la noche del 24 de marzo de 2017, fecha en que se conmemoraban los 41 años del golpe de estado de 1976, la propuesta consistió en una deriva por todas las baldosas por la memoria del barrio de Almagro (que, estadísticamente, es el barrio con mayor cantidad de detenidos-desaparecidos de la ciudad de Buenos Aires). Para ello, se convocó a actores, músicos, artistas visuales e investigadores. A cada uno se le asignó una baldosa para que realizara una acción en torno a ella. Fueron más de 40 acciones desarrollándose en simultáneo. Y se estima que asistieron más de 300 espectadores/participantes. El grupo de investigación que coordinó (el Grupo de Estudios sobre Teatro contemporáneo, política y sociedad en

4 Ficha técnica de Almagro tiene memoria disponible en línea.

5 En Verzero (2019) describo los Relatos situados realizados entre 2015 y 2018, desde una perspectiva enmarcada en la noción de "capitalismo emocional" de Eva Illouz. En ese artículo se reconstruyen las acciones pormenorizadamente. 
América Latina, IIGG-UBA) fue invitado a participar y algunos de los integrantes realizamos intervenciones en algunas baldosas.

Había cinco puntos de encuentro desde donde se partía: Casona Cultural Humahuaca (Humahuaca 3508), Elefante Club Teatro (Guardia Vieja 4259), Avalon Casa Cultural (Pringles 511), Umbral. Espacio de Arte (Av. Díaz Vélez 3980) y Comunarte (Av. Castro Barros 236). Cada participante llegaba a uno de los puntos de encuentro donde recibía una lista de detenidos-desaparecidos con la dirección de cada una de sus baldosas y un plano de la zona, y con ese material, realizaba su propia deriva. Esto constituye una diferencia sustancial respecto de Acción de memoria urbana (2015) y Una topografía de la memoria (2016), las dos obras de recorrido que el colectivo había realizado anteriormente, en las que todos los participantes salían en un solo grupo. Aquí cada uno realizaba su propio recorrido. Junto con el mapa y la lista de baldosas, se les indicaba que la experiencia duraba una hora y media, y que al final debían acercarse a la Plaza Almagro. Con esta información, cada participante, solo o con quien hubiera ido a participar de la obra, emprendía su viaje. Y cada performer tenía la indicación de que debía realizar su acción cada vez que se acercara algún participante. En la Plaza Almagro se realizó un encuentro musical de cierre.

No se cobró entrada -como en las acciones anteriores-, sino un bono contribución con el que se colaboró con "Barrios x Memoria y Justicia". Este evento, además, fue declarado de Interés para la Promoción y Defensa de los Derechos Humanos por la Legislatura porteña.
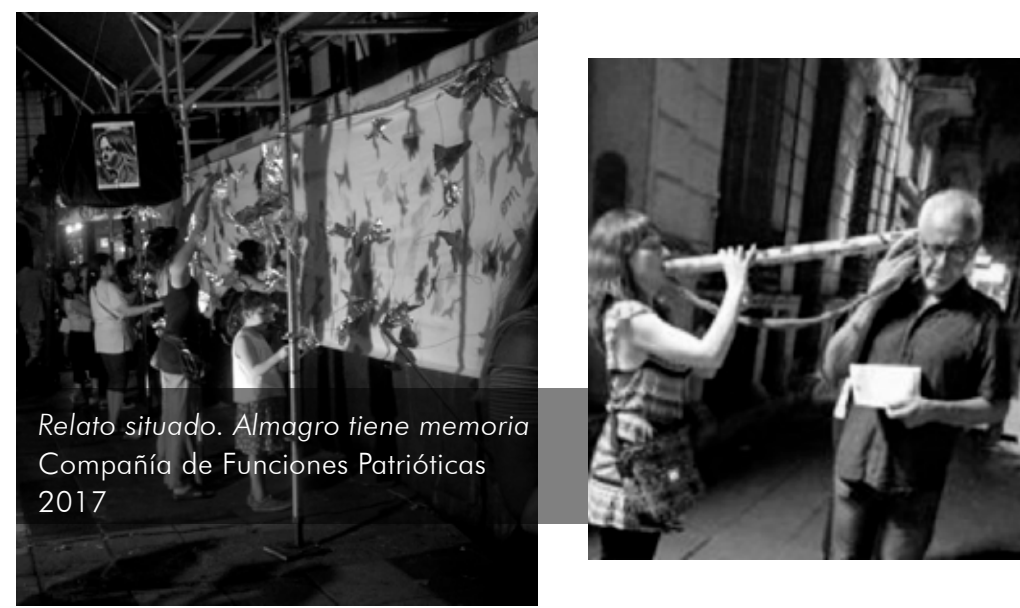
Almagro tiene memoria resultó un verdadero encuentro entre los cuerpos, masivo e íntimo al mismo tiempo. La mayoría de los performers (entre 40 y 50) y público (alrededor de 300 personas) asistió a esta deriva urbana al volver de la habitual marcha del 24 de marzo. La marcha de ese año, 2017, fue masiva, conmovedora y se definió por los lazos de unión de un sector social movilizado emocionalmente a un año de iniciado el gobierno por el que la coalición de derecha Cambiemos llegó al poder con Mauricio Macri como presidente de la nación.

Tuve la oportunidad de realizar una acción esa noche. Me tocó trabajar sobre la baldosa de Silvio Frondizi y su yerno, Luis Ángel Mendiburu. Un documento con pautas y criterios generales circuló entre los performers invitados, pero no tuvimos ningún condicionamiento ni limitación a la hora de construir la acción. Como mencioné, la consigna que nos dieron era que cada vez que llegara un espectador debíamos realizar la acción. El público hacía el recorrido individualmente, en parejas o en grupo, como quisieran, y se unían a otros o tomaban una deriva hacia otra baldosa. Así, hicimos cada acción durante una hora y media para una, dos, tres o veinte personas.

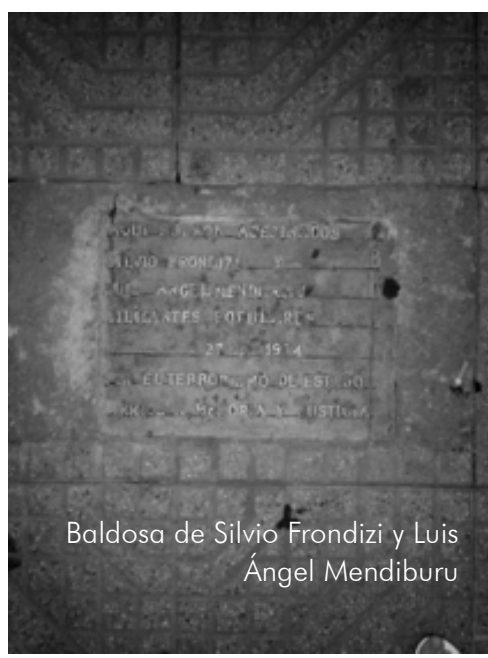

En esa acción reflexiono en torno a la identidad y a los pequeños impulsos que lanzan destinos diversos, a partir de la vestimenta como hilo conductor que surgió durante la investigación de un relato Laura Lina, compañera integrante de la Compañía de Funciones Patrióticas. En la acción relataba un sencillo hecho que me contó Laura de la siguiente manera:

Resulta que la abuela de Laura vendía sweaters. Y su abuelo, Isidoro, era muy amigo de Silvio. Una semana antes de que lo mataran, Isidoro le había regalado uno de esos sweaters que vendía su mujer. Era un sweater de los de rombos, clásico. Cuando se encontró el cadáver, Silvio llevaba puesto ese sweater.

Pensamos que podía ser bordeaux. O azul. Pero no encontramos ninguna foto. La única [saca una foto del bolsillo y la muestra] es esta. Es una foto de Silvio muerto. Pero no se reconoce el sweater. Tampoco se lo reconoce a Silvio en esta foto $(\mathrm{s} / \mathrm{n})$. 
Mientras lo decía, me cambiaba la ropa que llevaba puesta por otra. La acción finalizaba con el siguiente texto:

[Poniéndose un abrigo, mientras señala el vestido que lleva puesto:] Este vestido me lo regaló una amiga para mi último cumpleaños.

[Guardando todo en una mochila:] En realidad, me había regalado una blusa, pero me iba grande y la fui a cambiar. Era blanca, como con un entramado en la espalda. Mientras me estaba probando el vestido, vi que otra chica se llevaba la blusa. Y pensé: "Acabo de torcerle el destino a la blusa. Y al vestido también." [Sale].

La acción es muy simple e intenta generar una trama de memorias individuales con una memoria colectiva, acortando las temporalidades, detectando los usos que nos unen.

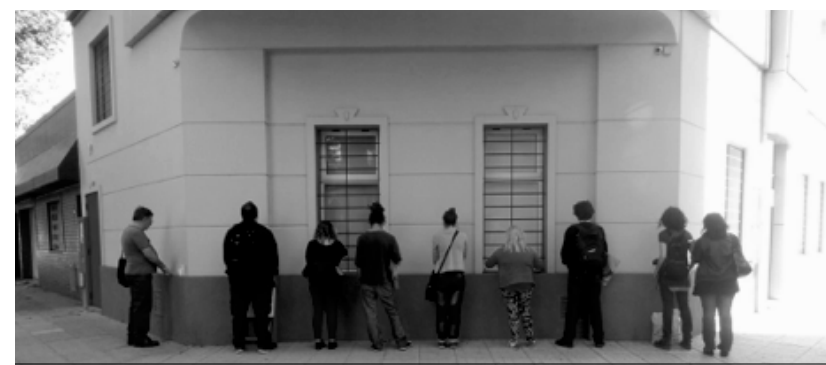

El esquinazo, en Sobre Falcón

Compañía de Funciones Patrióticas

30 de abril de 2017

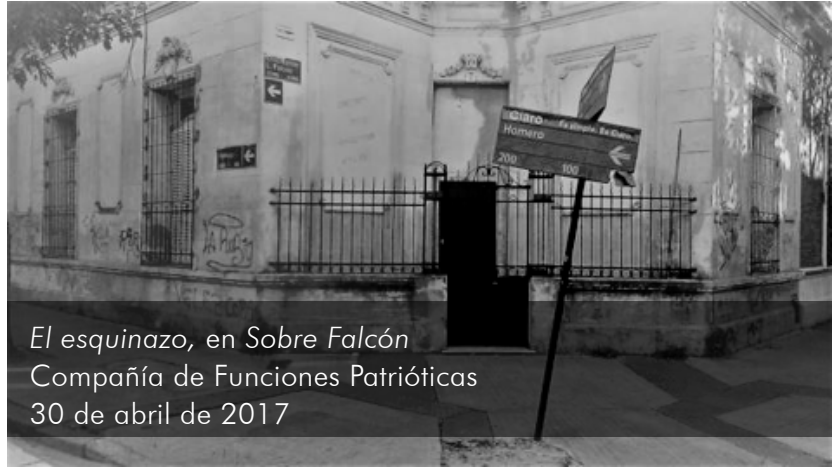


El Esquinazo $0^{6}$ formó parte de Sobre Falcón, ${ }^{7}$ un evento artístico multidisciplinario que involucró a artistas y a activistas en la realización de intervenciones, performances, pegatinas y diverso tipo de acciones a lo largo de la calle Falcón, que recorre los barrios de Vélez Sarsfield, Liniers, Villa Luro, Floresta, Flores y Caballito. La acción se hizo el domingo 30 de abril de 2017, día previo a la conmemoración del día del trabajador. La difusión se hizo de manera cerrada, a través de mails y por inbox de las redes, sólo a conocidos por cuestiones de seguridad, para evitar la presencia policial. El evento culminó con un picnic en la plaza Falcón, ubicada en la esquina de las calles Falcón y Benedetti, en el barrio de Floresta, más o menos en un punto medio del recorrido de la calle.

Falcón fue el primer cadete recibido del Colegio Militar y participó de la Conquista del Desierto. Se lo conoce por haber sido el Jefe de Policía que el $1^{\circ}$ de mayo de 1909 estuvo al frente del operativo policial que reprimió una movilización de la FORA (Federación Obrera Regional Argentina), matando e hiriendo a trabajadores. Meses después, el militante anarquista inmigrante ruso-ucraniano Simón Radowitzki vengó el hecho con una bomba que mató al policía represor. El gobierno de aquella época homenajeó al represor con una de las calles más extensas de la ciudad de Buenos Aires. Durante la última dictadura, una plaza del barrio de Floresta recibió también su nombre.

Distintos colectivos se encargaron de intervenir alguna zona de la calle. El esquinazo se ocupó de un sector del barrio de Villa Luro, un barrio de clase media, de casas bajas, alejado del centro. En esa zona, varias de las calles que cruzan Falcón llevan el nombre de poetas y músicos clásicos: Byron, Dante, Manzoni, Leopardi, Homero y Donizetti.

La propuesta de la Compañía de Funciones Patrióticas consistió en intervenir las esquinas, de manera que cada performer tuvo a su cargo una intersección en la que se gerena un cruce entre Falcón y un representante de la alta cultura occidental.

En mi caso, me encargué del cruce de Falcón y Manzoni. De las cuatro esquinas disponibles, elegí una en la que se encontraba una florería y a la hora en la que se darían las funciones (15 y 16 hs.) el sol la ilumina de frente. El día de la acción yo me encontraría de viaje, por lo que fue la performance filmada con anticipación.

$6 \underline{\text { Registro audiovisual }}$

7 Material de archivo 
La acción consistió, entonces, en la proyección de una acción realizada en otro momento pero en el mismo lugar y a la misma hora. La zona es casualmente muy familiar para mí, viví cerca en mi infancia e incluso en ese momento vivía cerca también. A partir del conocimiento en el cuerpo de la zona, me propuse reflexionar

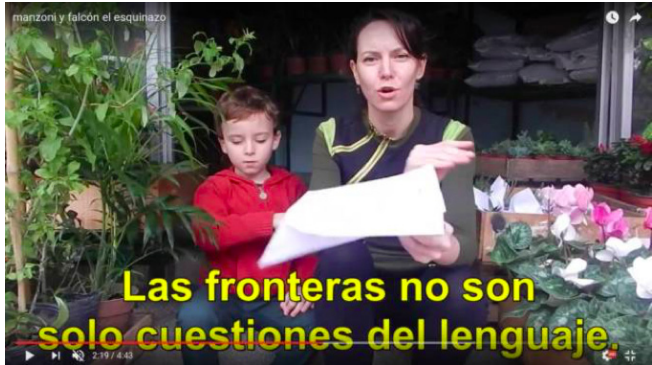

El esquinazo, en Sobre Falcon Compañia de Funciones Patrióticas 30 de abril de 2017 ralidades, sobre el migrar y el emigrar, la materialidad de la presencia. Sentados en el umbral de la florería con mi hijo, que entonces tenía cinco años, yo decía el texto mientras ambos armábamos avioncitos de papel y los tirábamos (una destreza que aprendió para la ocasión). Fue, en definitiva, un trabajo sobre las memorias, sobre los recuerdos en el cuerpo de la zona, sobre la infancia, la experiencia de ser migrante, de cruzar las fronteras y de proyectar esos pasados en los futuros posibles.

Dado que la propuesta consistió en la reproducción de una acción que ocurrió en un tiempo anterior, en el preciso momento de la intervención la proyección implicó un desdoblamiento y duplicación del presente: esto que está aquí ocurriendo ahora en realidad ocurrió en otro tiempo. Lo que vemos no es lo que está presente, sino que vemos lo sido, lo que alguna vez fue. Al mismo tiempo, la acción proyecta a través de algunos elementos (como el niño y los aviones lanzados al espacio infinito) lo que puede ser en un futuro incierto: si lo sido está siendo ahora, puede volver a ser.

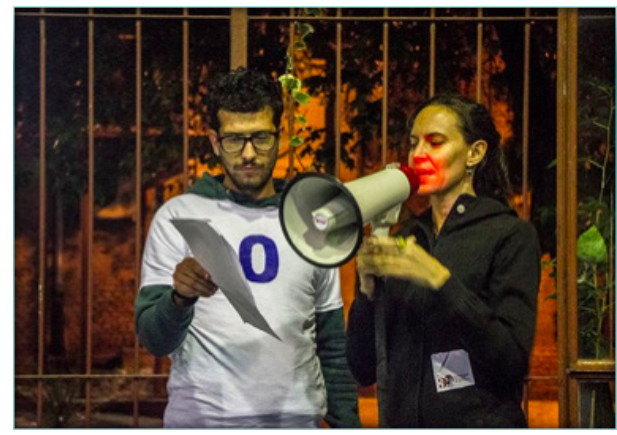

UNQ tiene memoria

Compañía de Funciones Patrióticas Universidad Nacional de Quilmes 26 de marzo de 2018
Me interesa reflexionar en torno a los futuros posibles que guardan experiencias de este tipo, tanto desde sus posibilidades, como desde los problemas que encarnan.

La experiencia como parte de las acciones y mi trabajo investigativo me permiten confirmar algunos planteos formulados por diversos colectivos a la hora de ser entrevistados. En primer lugar, es indudable el carácter colectivo y colaborador a partir del cual estas acciones construyen 
formas de asociación enriquecedoras. Estas experiencias poseen una capacidad de transformación micropolítica, que comienza con la posibilidad de modificar al menos mínimamente a los sujetos que participan de ellas (tanto a quienes las realizan como al público). Del mismo modo, su accionar en el "entre" lo individual y lo colectivo pone en juego una trama de sentidos que nos implica en diferentes dimensiones, poniendo en valor lo que ocurre en ese espacio "in-between-ness".

Asimismo, y de cara a aquellos futuros que podamos imaginar, resulta central observar algunos problemas que subyacen a la intervención artístico-política contemporánea, evitando el encantamiento que se produce por algunos componentes sustanciales del artivismo, como el carácter en ocasiones festivo del encuentro. Manuel Delgado enuncia tal vez de manera algo irónica pero muy ilustrativa el riesgo que encarna esta cuestión: "[el nuevo estilo de arte político tiene la] pretensión de rasgar la realidad cotidiana, cuando lo que hace es quizás sólo elevar la fiesta sorpresa a la altura al mismo tiempo de forma de lucha y de género artístico" (78).

Otro riesgo consiste en terminar siendo funcionales al mismo sistema que el artivismo cuestiona, y esto puede darse a través de la transformación de la acción artivista en parte de la oferta cultural de la ciudad. El límite difuso entre visibilización y espectacularización hace a la complejidad de esta problemática. La espectacularización — que Delgado define gráficamente como "convertir a las ciudades en parques temáticos" (73) — constituye una forma de esa acción devenida en objeto de consumo cultural.

En definitiva, el tipo de intervenciones artístico-políticas que tuvieron lugar en las ciudades latinoamericanas hasta el inicio de la pandemia por Covid-19 tienden lazos hacia futuros no exentos de riesgos, pero repletos de potenciales capacidades de transformación. A fines de mayo de 2020, cuando ya llevábamos unos meses de experiencia de confinamiento, Nelly Richard ${ }^{8}$ hacía referencia a la revuelta chilena de octubre de 2019 como un "tiempo que quedó congelado" y proponía pensar esas experiencias como archivo. Partiendo de sus reflexiones, considero que podemos concebir las acciones llevadas a cabo en el marco de la revuelta chilena como parte del repertorio que se ha forjado en América Latina y que -como dice Richard- es preciso mantener a disposición, como parte de las memorias disponibles que puedan ser retomadas críticamente a la hora de inventar futuros alternativos a los que nos ofrece el status quo, es decir, a cada hora en la que nos propongamos incidir sobre nuestro presente.

8 En conversación con Marcelo Expósito. La conversación originalmente apareció en: Marcelo Expósito, "Conversaciones para pensar un mundo en cuarentena": culturaunam.mx, 28 de mayo de 2020. 


\section{Obras citadas}

Bédarida, Francois. "Definición, método y práctica de la Historia del Tiempo Presente". Cuadernos de historia contemporánea 20 (1998): 19-27.

Benjamin, Walter. "Tesis de filosofía de la historia". Discursos interrumpidos I. Madrid: Taurus, 1973 [1940]: 175-191.

Benjamin, Walter. Libro de los pasajes. Madrid: Akal, 2005 [1927, 1940, 1982].

Delgado, Manuel. "Artivismo y pospolítica. Sobre la estetización de las luchas sociales en contextos urbanos". QuAderns-e. Institu Catalá d'Antropologia, Núm. 18 (2), 2013: 68-80.

Díaz Munizaga, Diego Miguel. "La historia del tiempo presente. Breve revisión a la disciplina del estudio histórico de las dinámicas de la sociedad actual", Abordajes UNLaR. Volumen 1, Número 2, Segundo Semestre, 2013: 1-25. http://ppct. caicyt.gov.ar/index.php/abordajes/article/view/4439/4121

Mate, Reyes. Medianoche en la bistoria. Comentarios a las tesis de Walter Benjamin "Sobre el concepto de historia”. Madrid: Trotta, 2006.

Roussó, Henry. "Desarrollos de la historiografía de la memoria", Conferencia pronunciada en la Universidad Nacional de La Plata, 15 de noviembre de 2017, Aletheia, volumen 8, número 16, junio 2018. http://sedici.unlp.edu. ar/bitstream/handle/10915/68329/Documento completo.doc.pdf-PDFA. pdf? sequence $=1$ \&is Allowed $=y$

Roussó, Henry. La dernier catastrophe. L bistoire, le present, le contemporain. Gallimard: París, 2012.

Verzero, Lorena. Teatro militante. Radicalización artística y política en los años '70. Buenos Aires: Biblos, 2013.

Verzero, Lorena. "Cuerpos sobre cuerpos: políticas de construcción de la historia reciente en el teatro argentino." Democracias incompletas. Debates críticos en el Cono Sur. Eds. Fernando Blanco y Cristián Opazo. Santiago de Chile: Cuarto propio, 2019: 195-220.

Verzero, Lorena. "Cartografía afectiva de la patria: Relatos situados, la ciudad palimpsesto". Entre/telones y pantallas. Afectos y saberes en la performance argentina contemporánea. Coords. Cecilia Sosa, Jordana Blejmar y Philippa Page. Buenos Aires: Libraria, 2020: 150-171. 